\title{
Francisco Rojas Claros, Dirigismo cultural y disidencia editorial en España (1962-1973). Alicante: Publicaciones Universidad de Alicante, 2013, 346 págs.
}

Este trabajo de Francisco Rojas Claros es fruto de su tesis doctoral homónima, que defendió en 2011 en la Universidad de Alicante. Su investigación se inscribe en la línea de la labor del profesor Francisco Sevillano Calero en torno al concepto de dialéctica poder/oposición en el ámbito de los medios de comunicación durante la era franquista. Ahora bien, el autor determinó encaminarse hacia el estudio del sector editorial "de avanzada", retomando así una expresión acuñada entre los años veinte y treinta del pasado siglo para referirse a una pujante corriente intelectual y editorial cuyo propósito fue editar y difundir ampliamente obras sumamente progresistas destinadas a ilustrar a un público popular sediento de cambio. Al calor de un creciente anhelo republicano, fueron prosperando iniciativas editoriales tan famosas como la Ciap, Cénit o Zeus.

Siguiendo una lógica análoga, Francisco Rojas eligió centrarse en un grupo de empresas editoriales como Ciencia Nueva, Edicusa, Ayuso o ZYX, que se constituyeron a principios y mediados de los años sesenta, en un período en que la dictadura franquista estaba iniciando un proceso de apertura muy relativa con el acceso de Manuel Fraga Iribarne al Ministerio de Información y Turismo, máxima autoridad en cuanto a censura de libros y dirigismo cultural. Si el antecesor de Fraga, Gabriel Arias Salgado, concebía su quehacer como una pugna por la moral mediante una férrea censura, Manuel Fraga pretendía modernizar la institución con el fin de mejorar la imagen del franquismo. Rojas demuestra ampliamente cómo la famosa Ley de Prensa de marzo de 1966 propició la eclosión de unos proyectos editoriales cada vez más ambiciosos y audaces frente a los principios de control de la opinión por parte del régimen. Sin embargo, el mérito del autor está en no caer en simplificaciones. Además de analizar cuidadosamente decenas de informes de censores, el autor ha podido acceder a otros documentos del Ministerio de Información que le han permitido ahondar en la estrategia de la Administración en cuanto al control del ámbito editorial de la época.

Esta obra evidencia, de manera sobradamente documentada, que la última fase del franquismo no significó un período de mayor tolerancia en cuanto a edición de libros, sino más bien una era de lucha entre unos editores cada vez más comprometidos y un Régimen llevado a un juego de tira y afloja entre el deseo de control de los contenidos culturales y la necesidad de construirse una imagen de modernidad comparable con otros países de Occidente.

En cuanto a las condiciones que permitieron la eclosión de un conjunto de editoriales comprometidas, el autor destaca la paulatina afirmación de ciertas corrientes intelectuales y la paralela elevación del nivel de formación universitaria, lo cual posibilitó la emergencia de grupos próximos al marxismo o a los sectores más progresistas de la Iglesia. Retomando el sugerente concepto de free spaces o "espacios de libertad", acuñado por los norteamericanos Sara Evans y Harry C. Boyte, el autor plantea aquellas editoriales como vectores autónomos de difusión de ideas en clara oposición con la dictadura franquista. Además, la labor de dichas editoriales no consistió únicamente en publicar textos con un contenido supuestamente subversivo desde el punto de vista franquista. El quehacer editorial cobraba todo su sentido si 
tenemos en cuenta el esfuerzo por hacer los textos asequibles al mayor número de lectores, realizando los libros en formatos más económicos, sacando tiradas importantes, utilizando las técnicas de impresión más novedosas y, sobre todo, introduciendo un paratexto editorial, esto es, presentaciones, prólogos y cronologías con el objetivo de orientar al lector hacia una interpretación más certera y con un mayor sentido crítico, especialmente cuando se trataban de obras desvinculadas, a primera vista, del contexto español de la época.

En cuanto al contenido propiamente dicho, el autor distingue cuatro temáticas que se impusieron a partir de los años sesenta: la introducción del marxismo en la renovación del pensamiento y las ciencias sociales; el catolicismo posconciliar progresista; la reconstrucción de la Historia en contra del relato mítico impuesto por el régimen y la recuperación de la llamada memoria histórica; y la España alternativa con la reivindicación de un país plural o pluralista. En una segunda fase, se daría una ampliación en cuanto a las temáticas abordadas, con el fin de ajustarse a la realidad española de la época, de manera no menos conflictiva. Así fue como las editoriales se abrieron a temas de política internacional en su vertiente más crítica (Cuba o Vietnam por ejemplo), al cuestionamiento de la enseñanza superior imperante en la época, a unos ensayos de tipo humorístico procedentes de la prensa crítica (siendo Triunfo uno de sus mejores proveedores) o al análisis sociopolítico de la España franquista en relación con el auge de las ciencias sociales.

Frente a este movimiento editorial, se organizó un aparato de censura estatal en torno a la nueva Ley de Prensa de 1966, con la aparente novedad de la desaparición de la censura previa al depósito legal. En realidad, dicha desaparición solo fue aparente puesto que, de hecho, la Administración "aconsejaba" recurrir al dispositivo de consulta voluntaria para evitar posibles consecuencias legales de parte del Tribunal de Orden Público (TOP). A partir de este marco jurídico, supuestamente más moderno y abierto, el autor demuestra, a partir de casos muy concretos y ampliamente documentados, cómo se fue instalando entre la censura y los editores un proceso dialéctico muchas veces áspero, que a la larga propiciará la publicación de textos críticos con el Régimen.

Pero en ningún momento se le olvida al autor que el franquismo era, por naturaleza, un régimen represivo. Pone de manifiesto un sinnúmero de medidas destinadas a contrarrestar aquella oleada de obras consideradas subversivas: desde las obras denegadas en la etapa de la consulta voluntaria, pasando por las obras denunciadas en el TOP, hasta el secuestro e, incluso, el cierre de algunas editoriales. Lo cierto es que, al respecto, el Régimen no vaciló en utilizar una herramienta extralegal para presionar a dichas editoriales: la inscripción obligatoria en un Registro de empresas editoriales. El autor demuestra que el Ministerio iba elaborando informes precisos sobre los antecedentes políticos de los integrantes de las editoriales con el fin de retrasar o denegar el número de registro de la empresa, lo cual podía suponer hasta la desaparición de la casa editorial. Además, es muy notable la obsesión de los censores por limitar la difusión de ciertas obras consideradas peligrosas, atendiendo a su tirada prevista y a su precio de venta, tal y como ocurría en tiempos de la dictadura de Primo de Rivera. Dicho de otro modo, se privilegiaban, desde el punto de vista del Ministerio, tiradas limitadas y precios elevados para evitar una difusión importante de la obra.

Por otra parte, la política del Ministerio en cuanto a censura no fue lineal sino que dependió en gran parte del titular del MIT y de las circunstancias políticas. 
Sin embargo, lo que demuestra Francisco Rojas es que, cualquiera que fuera la actitud de las autoridades, los protagonistas de aquellas editoriales "de avanzada" siempre llevaron a cabo una labor voluntariosa y valiente, intentando romper "el techo de lo publicable", costara lo que costara.

Paralelamente a su actuación represiva, también es de señalar que el Ministerio de Información ansiaba desarrollar una política "positiva" de dirigismo cultural, a modo de "compensación" de una dinámica editorial de signo crítico. Así fue como Manuel Fraga Iribarne impulsó el Instituto de Estudios sobre la Guerra Civil Española, al mando de Ricardo de la Cierva y, sobre todo, la famosa iniciativa de Libros RTV, cuyo objetivo era intentar competir en cierto modo con la oferta editorial de oposición, proponiendo una importante colección a precios asequibles, contando con una inmensa campaña de promoción, pero obviamente, sin la carga crítica de las editoriales independientes. Así y todo, queda demostrado que el Régimen resultó incapaz de conformar una política de dirigismo cultural positivo mínimamente eficiente, poco antes de que se diera una importante involución con la nominación en 1969 del Almirante Carrero Blanco para ocupar la Jefatura del Gobierno y la consecuente sustitución de Manuel Fraga por Alfredo Sánchez Bella. Esta nueva era estaría marcada por una creciente conflictividad entre el Ministerio y las editoriales de corte progresista, a la vez que por un mayor espíritu de resistencia de parte de dichas editoriales. A este respecto, subraya el autor que los últimos años de la dictadura e incluso los primeros años del postfranquismo correspondieron a un período de importante represión cultural, en cuanto a denuncias y secuestros de libros se refiere.

En definitiva, este libro supone una aportación fundamental y de obligada referencia en el conocimiento de la Historia cultural y del mundo editorial en la época franquista. En cuanto a las fuentes utilizadas, se trata de fuentes primarias, que constituyen un material de primera importancia y que nunca había sido utilizado de manera tan amplia, supliendo en gran parte la casi ausencia de archivos editoriales en España. La utilización masiva de informes de censura y las correspondientes cartas de editores en defensa de sus proyectos permite ofrecer una clara idea de la dialéctica que estaba en juego en aquella pugna por la libertad de expresión. De modo que este trabajo pone de manifiesto la importancia capital de los archivos procedentes del Ministerio de Información (más allá de los informes de censura) en el estudio de la cultura en la era franquista. Este análisis nos demuestra que el tardofranquismo fue un período durante el cual la resistencia cultural pudo darse de manera mucho más sutil que en la etapa anterior a 1962, debido a las posibilidades de negociación que concedía la Ley de Prensa. Otro aspecto, interesantísimo y absolutamente novedoso, es el intento de acercarse a un análisis sociológico de los "lectores", en referencia a los censores del Ministerio, incluyendo un listado de nombres con sus correspondientes formaciones y especialidades, llegando a la conclusión de que aquellas personas distaban mucho de ser individuos meramente caricaturescos o bestiales sino personas con un alto nivel de formación.

Además, es muy notable la cantidad de obras analizadas rigurosamente por el autor, tanto en su versión primera como en su versión "mutilada" por la censura, por no hablar de los libros que no pudieron publicarse en su tiempo. Semejante trabajo nos lleva a la conclusión de que la labor cultural llevada a cabo por aquellos editores resultó 
imprescindible para dar a toda una generación las debidas armas intelectuales necesarias para adentrarse en un proceso de transición hacia la democracia.

No obstante, dicho proceso progresista en los planes editoriales no fue exclusivamente un fenómeno minoritario llevado a cabo por unas casas comprometidas y vanguardistas. Si examinamos algunos catálogos editoriales, comprobamos que incluso casas tan importantes como Planeta empezaron a incorporar, a partir de 1973, colecciones abiertas y audaces como "Espejo de España", "Documento" o "Textos", bajo el impulso de su entonces director literario Rafael Borrás Betriu.

David Escobar Laplana

Lycée Victor Louis, Talence (Francia).

escobar.david@orange.fr

Fecha de recepción: 29 de julio de 2014.

Fecha de aceptación: 18 de agosto de 2014.

Publicado: 31 de diciembre de 2014.

Para citar: David Escobar Laplana, "Francisco Rojas Claros, Dirigismo cultural y disidencia editorial en España (1962-1973). Alicante: Publicaciones Universidad de Alicante, 2013, 346 págs.”, Historiografias, 8 (julio-diciembre, 2014): pp. 159-162. http://www.unizar.es/historiografias/historiografias/numeros/8/escobar.pdf 